\title{
Analysis of habitat characteristics of the scalloped spiny lobster Panulirus homarus (Linnaeus, 1758) in their home range along the southern coast of Sri Lanka
}

\author{
J. D. M. SENEVIRATHNA, GAYANTHA R. L. KODIKARA*AND D. H. N. MUNASINGHE \\ Department of Zoology, University of Ruhuna, Matara, Sri Lanka \\ "Department of Oceanography, University of Ruhuna, Matara, Sri Lanka \\ e-mail: jayanduminda@yahoo.com
}

\begin{abstract}
The present study was aimed to investigate the quality of home range habitat characteristics of the scalloped spiny lobster Panulirus homarus (Linnaeus, 1758) in southern coastal region of Sri Lanka. Four sites were selected from south-east (Patanagalle, Godawaya) and south-west (Weligama, Hikkaduwa) regions of the southern coast of Sri Lanka (SCSL). The bottom water quality data and benthic substrate types of their home range habitats were monitored and noted in a $25 \mathrm{x} 25 \mathrm{~m}$ area covering 16 subsampling points with locality information. With the use of geographical information system (GIS) tools, the spatial distribution maps of environmental parameters were created and submerged bottom substrate types of the four sites were graphed. Salinity, temperature and dissolved oxygen correlated well with depth. Hikkaduwa site was found rich in corals with less number of scalloped spiny lobsters. Sites of south-east region of the SCSL (Patanagalle, Godawaya) were found less polluted having rocks and sandy bottom with high occurrence of scalloped spiny lobsters. Results of the study showed that Patanagalle site (south-east of SCSL) could be suggested as the most suitable site for culturing scalloped spiny lobsters.
\end{abstract}

Keywords: GIS, Habitat mapping, Marine ecology, Panulirus homarus, Spiny lobster, Sri Lanka, Water quality

\section{Introduction}

More than 45 species of spiny lobsters (Family: Palinuridae) inhabit temperate and tropical seas from the intertidal zone to depths approaching $1000 \mathrm{~m}$ (Holthuis, 1995). According to Jayawickrama (1991) six species have been recorded from Sri Lanka viz., Panulirus. homarus, P. ornatus, $P$. versicolor, $P$. longipes, $P$. polyphagus and $P$. penicillatus, but currently only five species except P. polyphagus are found (Upul, 2009). Generally, only one or a few species of spiny lobsters co-occur in a particular region for e.g., $P$. elephas in the Mediterranean and $P$. argus and P. guttatus in the northern Caribbean. But in the southern coastal habitats of Sri Lanka, multiple species of spiny lobsters co-occur. $P$. homarus usually inhabits sand-stone reefs and rocks for shelter with pale turbid conditions of the surf zone to depths of $20 \mathrm{~m}$ in the continental shelf (Holthuis, 1991; Kulmiye and Mavuti, 2005).

Water quality parameters such as temperature salinity, dissolved oxygen, ammonia content and $\mathrm{pH}$ have shown significant effects on the immune system of crustaceans (Vargas et al., 1998; Le Moullac et al.,1998; Cheng and Chen, 2000, 2002; Lamela et al., 2005) which also play an important role on commercial lobster mariculture (Vidya and Shoji, 2012). Among these parameters, salinity is one of the major factors that may significantly affect the physiology, growth and survival of aquatic organisms (Bindhu et al., 2007) including lobsters (Vidya and Shoji, 2012). Dissolved oxygen and temperature of water are also critical factors affecting metabolic rate of spiny lobsters. Water temperature determine the growth rate of crustaceans (Hartnoll, 1982) and has been shown to affect the growth of a number of spiny lobster species including Jasus lalandii (Dubber et al., 2004), Jasus edwardsii (Crear et al., 2000; Thomas, et al., 2000), Panulirus. argus (Lellis and Russell, 1990), P. cygnus (Phillips et al., 1977), P. homarus (Kemp and Britz, 2008) and P. interruptus (Serfling and Ford, 1975). The optimum ranges of water quality parameters vary with different stages in the life cycle of spiny lobsters and preferable home range habitat conditions in certain locations can lead to increase in number of individuals in a relevant stock.

Habitat complexity provides refuges and barriers that fragment the area, resulting in more heterogeneous assemblages (Sebens, 1991). The complex ocean water current pattern of the southern coast of Sri Lanka (SCSL) shapes the habitat diversity seasonally. Also diurnal changes of the coastal area cause selection of a preferable home range habitat for scalloped spiny lobsters. 
Spatial habitat analysis can be applied for measuring and modeling spatial patterns in biotic variables, to understand the mechanisms that manage critical aspects of the ecology of species, such as their distribution (Legendre and Legendre, 1998; Liebhold and Gurevitch, 2002) and for lobster stock assessment (Evans et al., 1996). The Geographic Information System (GIS) can be successfully applied as a fundamental analysis tool in estimation of the spatial relationships between the occurrence of macrobenthos species and related environmental factors (Jong-Kuk et al., 2011).

There are several research findings of preferential habitats for different developmental stages of spiny lobsters in the Caribbean area (Childress and Herrnkind, 1996; Davidson et al., 2002). But studies on suitable home range habitat characteristics and habitat qualities of $P$. homarus in the Indian Ocean rare. The habitat diversity of the SCSL is very high and spiny lobsters in this region are not equally distributed even though there are dens with rocks and muddy sand which are their preferred habitats. The present investigation was undertaken to study the habitat characteristics of their home range along the southern coast of Sri Lanka aimed at formulation of suitable management strategies.

\section{Materials and methods}

Four sampling sites along the SCSL, comprising Hikkaduwa, Weligama, Godawaya (Ambalanthota) and Patanagalle (Yala-Kirinda) were selected based on the heterogeneity of the SCSL as well as based on the information gathered from lobster fishermen on areas of scalloped spiny lobster (P. homarus) abundance (Fig. 1).

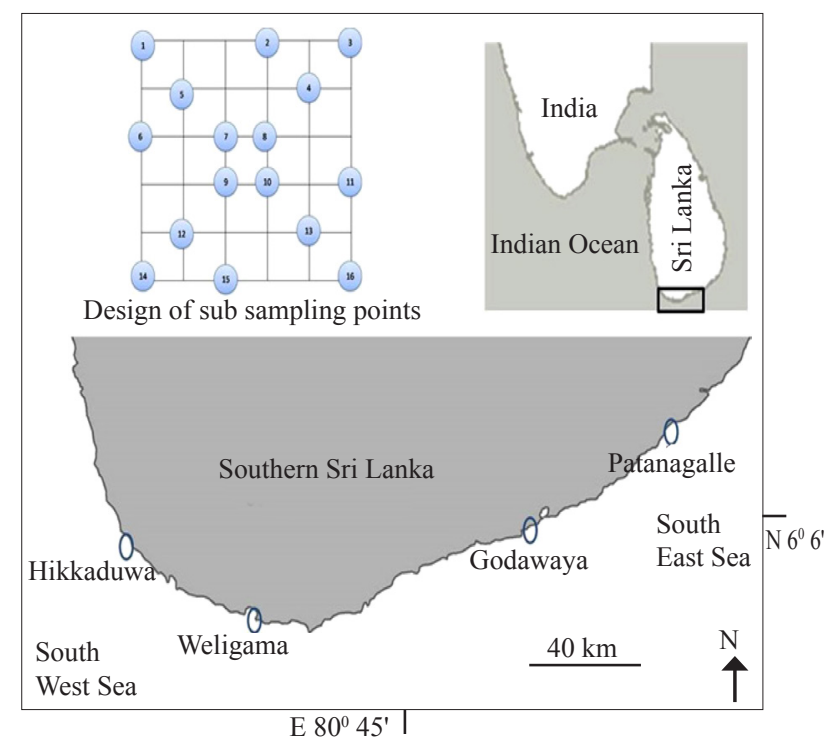

Fig. 1. Sampling sites of P. homarus in southern coast of Sri Lanka
Samples were collected from the selected sites during the period of calm weather during November to December 2012.

A fiberglass boat (12 feet long) with a $10 \mathrm{HP}$ engine was used for sampling. Water quality parameters and the benthic environment were monitored within an area of $25 \mathrm{~m}^{2}$ demarkated at each sampling site, with 16 subsampling points in each site as depicted in Fig. 1. Differential GPS (Pathfinder Pro XR Trimble Co., CA, USA) with $3 \mathrm{~m}$ horizontal accuracy was used for accurate positioning of the subsampling points. Bottom water samples were collected, observed number of lobsters were counted and bottom substrate types were noted at each sub-sampling point with the help of two SCUBA divers (Table 1). Depth of each subsampling point was measured using the depth gauge of the SCUBA diving kit. The recorded data in the field were noted on a waterproof slate for further use.

Temperature of the bottom water was measured just after collecting water samples using Ruthner water sampler (KC Denmark; 11.001) and salinity was measured using a salinity refractometer. Dissolved oxygen (DO) bottles $(250 \mathrm{ml})$ were filled with bottom water from each subsampling point and preserved using Winkler solutions $\mathrm{A}$ and $\mathrm{B}$ at the site and the DO level was estimated as per Strickland and Parsons (1968).

The significant mean differences of temperature, salinity, DO and depths between each site were tested by Kruskal-Wall non-parametric test $(\mathrm{p}<0.05)$. Water quality parameters of the four sites were pooled and the Spearman correlation method was used to test correlation between the different parameters separately. All the statistical analyses were done using SPSS version 20.

Water quality parameters and depths of sixteen subsampling points in each site were used for spatially mapping of habitat quality. The locality information of each site was noted in degrees using GPS meter (Pathfinder Pro XR Trimble Co., CA, USA; $\pm 1 \mathrm{~m}$ ) and those data were converted into meters by GeoCalc 4.2 software. Environmental parameters were re-arranged in an excel sheet with $\mathrm{X}$ and $\mathrm{Y}$ coordinates to prepare spatial distributional maps. Physicochemical parameters were spatially mapped by interpolating attributes of subsampling points of each site by Natural Neighbor Interpolation Technique in ArcGIS 10.1 version.

\section{Results}

The locality information of the each sampling site is included in Table 1. The habitat quality of $P$. homarus has been defined by various environmental factors including temperature, salinity, DO, depth 
Table 1. Details of geographic distribution, abundance of lobsters and average environmental parameters of selected sampling sites

\begin{tabular}{|c|c|c|c|c|c|c|c|c|c|}
\hline \multirow[b]{2}{*}{ Sampling site } & \multirow[b]{2}{*}{ Region } & \multirow[b]{2}{*}{$\begin{array}{l}\text { Date of } \\
\text { sampling }\end{array}$} & \multirow[b]{2}{*}{ Latitude } & \multirow[b]{2}{*}{ Longitude } & \multirow[b]{2}{*}{$\begin{array}{l}\text { No. of } \\
\text { lobsters } \\
\text { observed }\end{array}$} & \multicolumn{4}{|c|}{ Average values of environmental parameters } \\
\hline & & & & & & Temperature $\left({ }^{\circ} \mathrm{C}\right)$ & Salinity (\%) & $\mathrm{DO}\left(\mathrm{mg} \mathrm{l}^{-1}\right)$ & Depth (m) \\
\hline Hikkaduwa & South-west & $16 / 11 / 2012$ & $\begin{array}{l}06^{\circ} 07^{\prime} 45.4^{\prime \prime}-06^{\circ} 07^{\prime} \\
46.2^{\prime \prime} \text { North }\end{array}$ & $\begin{array}{l}80^{\circ} 05^{\prime} 49.9^{\prime \prime}-80^{\circ} 05^{\prime} \\
50.7^{\prime \prime} \text { East }\end{array}$ & 26 & $28.344 \pm 0.397$ & $37.063 \pm 1.124$ & $8.113 \pm 1.744$ & $11.019 \pm 1.411$ \\
\hline Waligama & South-west & $26 / 09 / 2012$ & $\begin{array}{l}05^{\circ} 56^{\prime} 36.5^{\prime \prime} 05^{\circ} 57^{\prime} \\
38.1^{\prime \prime} \text { North }\end{array}$ & $\begin{array}{l}080^{\circ} 28^{\prime} 020^{\prime \prime}-080^{\circ} 27^{\prime} \\
031^{\prime \prime} \text { East }\end{array}$ & 28 & $28.063 \pm 0.629$ & $36.313 \pm 0.544$ & $7.488 \pm 0.797$ & $7.863 \pm 1.823$ \\
\hline Godawaya & South-east & $15 / 10 / 2012$ & $\begin{array}{l}06^{\circ} 06^{\prime} 24.3^{\prime \prime}-06^{\circ} 06^{\prime} \\
25.1^{\prime \prime} \text { North }\end{array}$ & $\begin{array}{l}081^{\circ} 03^{\prime} 20.3^{\prime \prime}-081^{\circ} 03^{\prime} \\
21.1^{\prime \prime} \text { East }\end{array}$ & 34 & $27.781 \pm 0.446$ & $36.188 \pm 0.680$ & $5.900 \pm 0.826$ & $5.756 \pm 1.188$ \\
\hline Patanagalle & South-east & $8 / 11 / 2012$ & $\begin{array}{l}06^{\circ} 20^{\prime} 32.9^{\prime \prime}-06^{\circ} 20^{\prime} \\
34.6^{\prime \prime} \text { North }\end{array}$ & $\begin{array}{l}081^{\circ} 30^{\prime} 3.8^{\prime \prime}-081^{\circ} 30^{\prime} \\
4.9^{\prime \prime} \text { East }\end{array}$ & 72 & $28.594 \pm 0.455$ & $35.156 \pm 0.747$ & $7.800 \pm 1.613$ & $8.113 \pm 1.925$ \\
\hline
\end{tabular}

and type of bottom substrate in this study. Spatial distribution of environmental parameters of the four selected sites in the SCSL are represented in Fig. 2 and 3.

The average water quality parameters and observed number of lobsters in each site are presented in Table 1. Highest number of individuals (72) of scalloped spiny

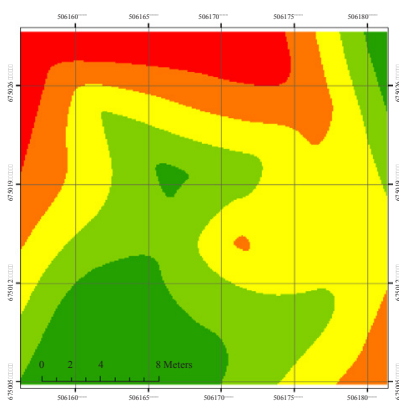

a (i)

Depth (m)

$\square$ 4.20-4.96 $\square 4.96-5.56 \quad \mathrm{~N}$

$\square$ 5.56-6.17 $\square 6.17-6.90 \quad \uparrow$

ㄴ.90-7.97

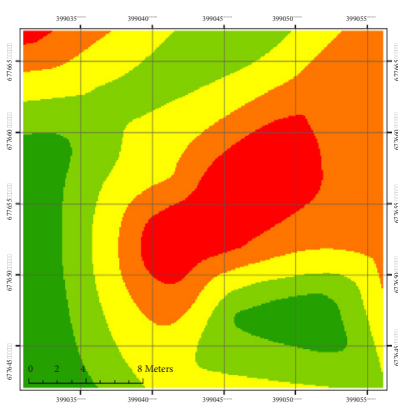

b (i)

Depth (m)

$\square$ 8.69-9.93 $\square 9.93-10.72 \mathrm{~N}$

$\square$ 10.72-11.43 $\square$ 11.43-12.08

- 12.08-13

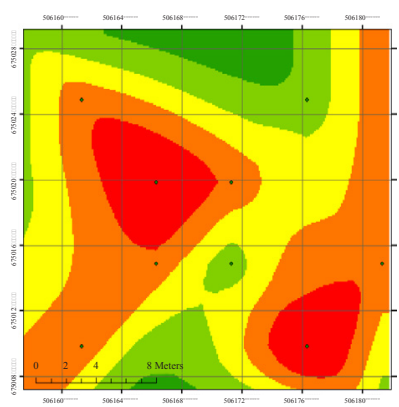

a (ii)

Temperature $\left({ }^{\circ} \mathrm{C}\right)$

$\square$ 27.00-27.41 $\square 27.41-27.65 \mathrm{~N}$

$\square$ 27-65-27.84 $\square 27.84-28.06$ 个

口 28.06-28.48

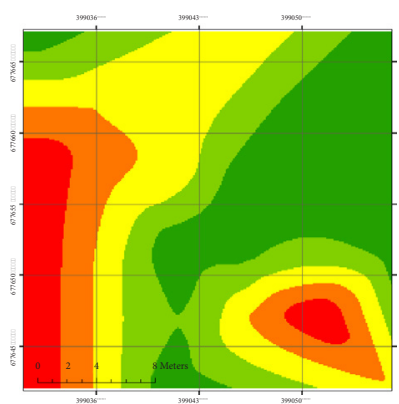

b (ii)

Temperature $\left({ }^{\circ} \mathrm{C}\right)$

$\square$ 28-28.14 $\square 28.14-28.33 \mathrm{~N}$

$\square$ 28.33-28.53 $\square$ 28.53-28.74

$\square$ 28.74-29

lobsters was recorded in Patanagalle (south-east). Average water quality parameters in the site showed highest temperature $\left(28.594 \pm 0.455^{\circ} \mathrm{C}\right)$, lowest salinity $(35.156 \pm 0.747 \%)$ and medium values of DO $\left(7.800 \pm 1.613 \mathrm{mgl}^{-1}\right)$ as well as depth $(8.113 \pm 1.925 \mathrm{~m})$.

There was no significant difference in the mean water quality parameters among four different sites

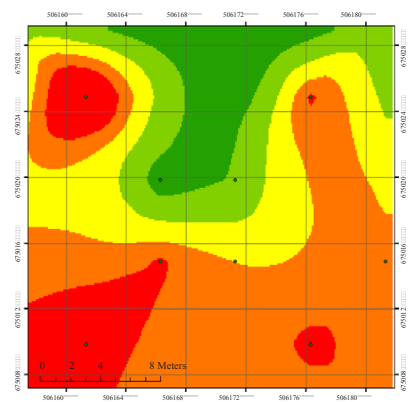

a (iii)

Dissolved oxygen $\left(\mathrm{mg} \mathrm{l}^{-1}\right)$

$\square$ 4.275-5.146 $\square 5.146-5.620 \mathrm{~N}$

$\square$ 5.620-6.005 $\square 6.005-6.333 \quad$ 个

$\square 6.333-7.158$

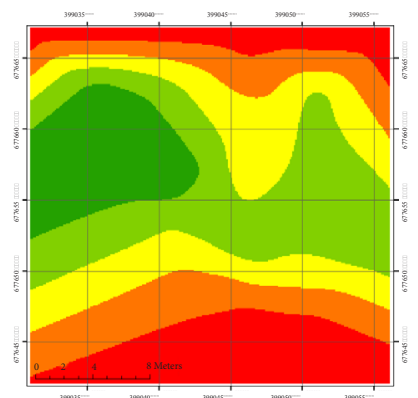

b (iii)

Dissolved oxygen $\left(\mathrm{mg} \mathrm{l}^{-1}\right)$

$\square$ 5.19-6.49

$\square 7.45-8.24$

$\square$ 9.07-9.98

$\square 8.24-9.07$

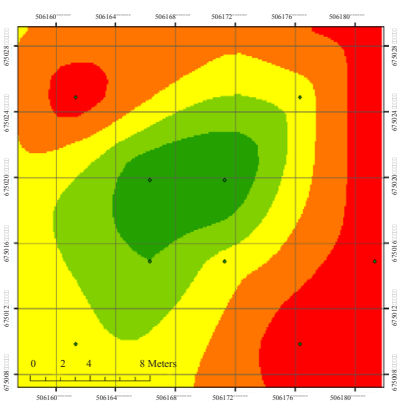

a (iv)

Salinity (ppt)

$\square$ 35.015-35.496 $\square 35.498-35.856 \mathrm{~N}$ $\square 35.856-36.214 \square 36.214-36.642 \uparrow$

— 36.642-37

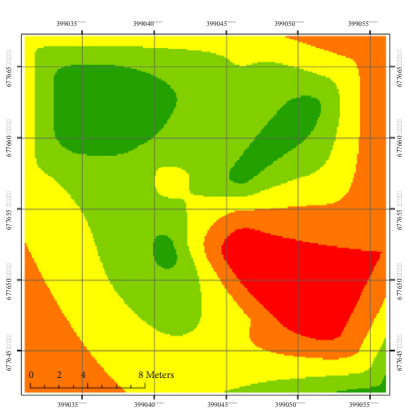

b (iv)

Salinity (ppt)

$\square 6.49-7.45 \quad \mathrm{~N} \quad \square 35-36.22$

$\square$ 36.22-36.74 N

$\square 37.30-38.02 \uparrow$

Fig. 2. Spatial distribution of environmental parameters of the sampling sites. (a) Godawaya, (b) Hikkaduwa

(i) Depth, (ii) Temperature, (iii) Dissolved oxygen, (iv) Salinity 


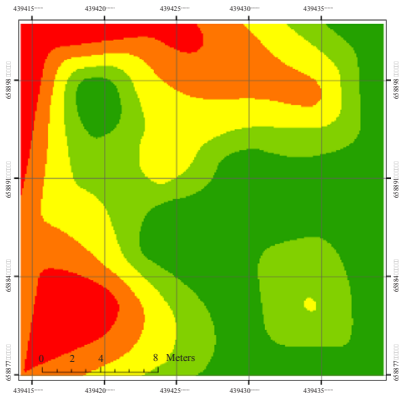

c (i)

Depth (m)

$\square$ 5.69-7.06 $\square 7.06-7.78 \quad \mathrm{~N}$

$\square 7.78-8.57 \quad \square 8.57-9.43 \quad \uparrow$

$\square$ 9.43-11.30

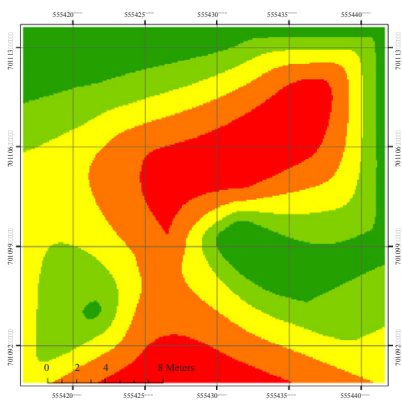

d (i)

Depth (m)

$\square$ 5.51-7.02 $\square 7.02-7.81$

$\square 7.81-8.62 \quad \square 8.62-9.60 \quad \uparrow$

$\square$ 9.60-11.10

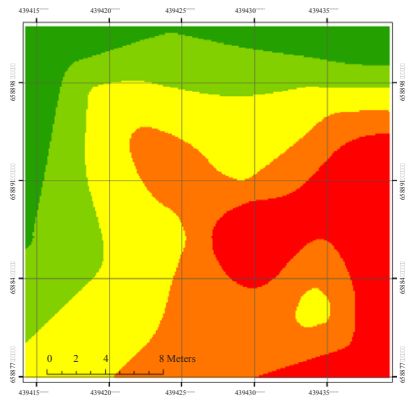

c (ii)

Temperature $\left({ }^{\circ} \mathrm{C}\right)$

$\square$ 27-27.54 $\square$ 27.54-27.87 N

$\square$ 27.87-28.2

- 28.53-29

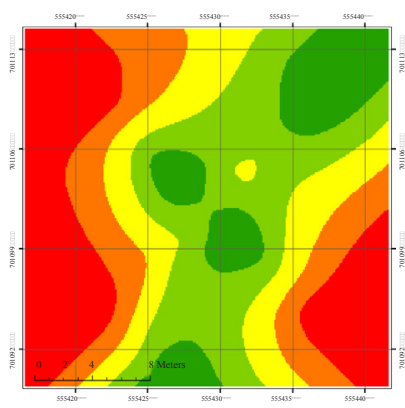

d (ii)

Temperature $\left({ }^{\circ} \mathrm{C}\right)$

$\square$ 28-28.24 $\square$ 28.24-28.43 N

$\square$ 28.43-28.63 $\square$ 28.63-28.84

— 28.84-29

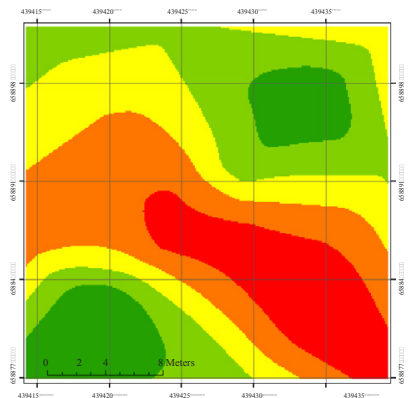

c (iii)

Dissolved oxygen $\left(\mathrm{mg} \mathrm{l}^{-1}\right)$

$\square$ 1.54-1.71 $\square 1.71-1.82$

$\square$ 1.82-1.91

$\square$ 2.02-2.20

$\square 1.91-2.02$

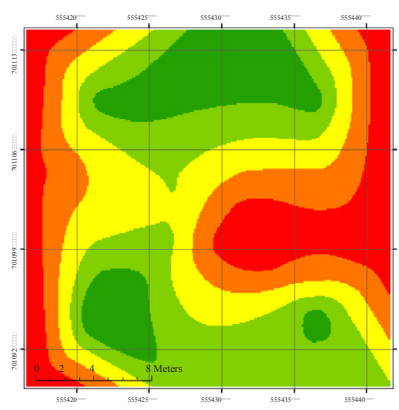

d (iii)

Dissolved oxygen ( $\left.\mathrm{mg} \mathrm{l}^{-1}\right)$

$\square$ 1.39-1.66

$\square$ 1.82-1.99

- 2.18-2.25

$\square 1.99-2.18$

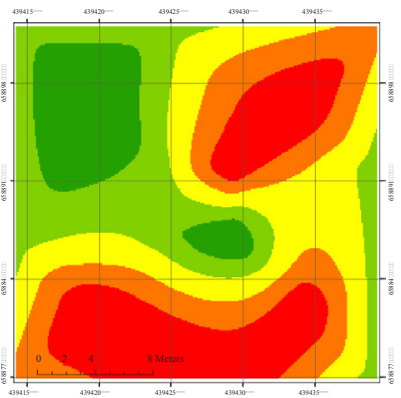

c (iv)

Salinity (ppt)

$\square$ 35.5-35.88

$\square 36.13-36.40$

口 36.67-37

$\square 35.88-36.13 \quad \mathrm{~N}$

$\square 36.40-36.67 \uparrow$

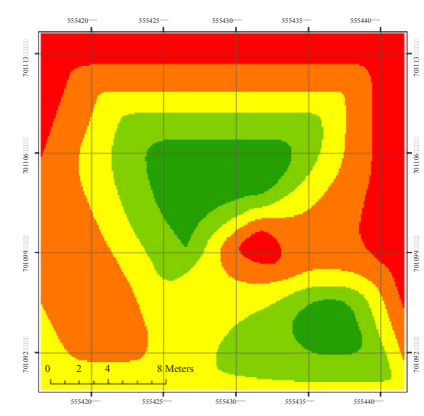

d (iv)

Salinity (ppt)

$\square 1.66-1.82$

$\square$ 34-34.52

$\square$ 34.88-35.2

$\square$ 34.52-34.88 N

- 35.56-36

Fig. 3. Spatial distribution of environmental parameters of the sampling sites. (c) Weligama, (d) Patanagalle

(i) Depth, (ii) Temperature, (iii) Dissolved oxygen, (iv) Salinity

( $\mathrm{p}>0.05)$. According to Spearman correlation analysis, non-significant negative correlation was observed between temperature vs depth as well as temperature $v s$ salinity. Non-significant positive correlation between temperature $v s$ DO; salinity $v s$ depth, salinity $v s$ DO and depth vs DO was found. Significant positive correlation $(p<0.05)$ was observed between temperature and DO.

Fig. 4. explains the distribution of bottom substrate conditions of different sites where $P$. homarus are abundant. The bottom of Hikkaduwa and Weligama (south-west) sites mostly comprised coral, sand and rocky substrates. Hikkaduwa site was rich with more coral (44\%) and less muddy sand substrate $(25 \%)$ while Weligama site was rich in muddy sand (44\%) with less corals (19\%). Patanagalle and Godawaya (south-east) sites were rich with rock and sand substrates, where there was no coral. More than $60 \%$ of the Patanagalle site had rocks and rest of the habitat was muddy with coarse sand. Godawaya site had small amount of silt $(13 \%)$ with much of muddy and coarse sands $(50 \%)$.

\section{Discussion}

Environmental parameters are very important which determine suitable habitat conditions for spiny lobsters. Results of the present study show the patterns of bottom substrate conditions and quality of environmental parameters of different home range habitats of P. homarus frequently abundant in the SCSL. Environmental factors affect age, growth, survival and reproduction including molt stage, social conditions and nutrition of the lobsters (Kemp and Britz, 2008; Vidya and Shoji, 2012). Also they can act singly or in combination to cause sub-lethal stress on lobsters. Temperature, salinity and DO are major factors which affect the biology of lobsters (Bindhu et al., 2007; Kemp and Britz, 2008). Studies have found that adults are more resistant to fluctuations and extremes in temperature, salinity and DO than earlier life stages. The bottom substrate conditions could influence changes in these environmental parameters. Pollution by tourism activities in the SCSL also affects home range habitat characteristics and abundance of lobsters in the area. 


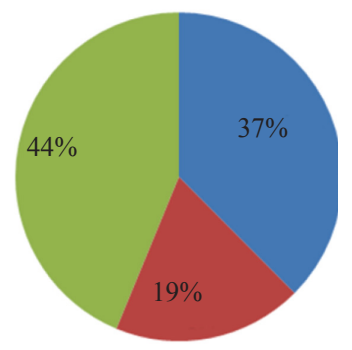

(a)

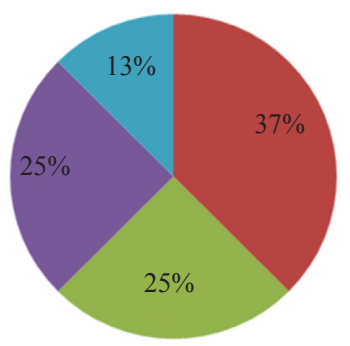

(b)

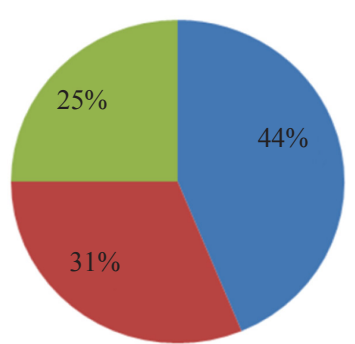

(c)

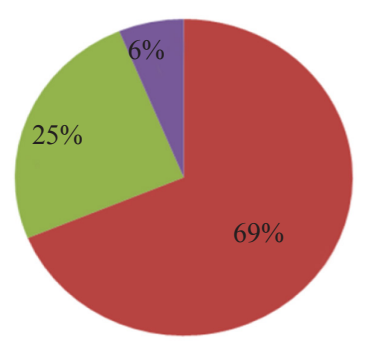

(d)

Coral, $\square$ Rock, $\square$ Muddy sand, $\square$ Coarse sand, $\square$ Slit

Fig. 4. Percentage of bottom substrate conditions of the four selected habitats

Temperature fluctuations may reduce growth and increase mortality of lobsters. Results of the present study shows that at low depths, water temperature and DO are having a higher positive correlation. Several studies of temperature effects on lobster embryo development (Perkins, 1972; Aiken and Waddy, 1986) and larval development (Hughes and Matthiessen, 1962; Charmantire et al., 1991) have been done. Offshore areas, which are generally cooler, appear to produce larger first stage larvae than inshore waters (Rogers et al., 1968). Cooper and Uzmann (1980) estimated that pre-adult lobsters tolerate temperatures from 18 to $30.5^{\circ} \mathrm{C}$ at optimal DO and salinity levels. Temperature range recorded for scalloped spiny lobster habitats in the present study was $27-29^{\circ} \mathrm{C}$ and this could be an average optimum temperature for $P$. homarus with the optimum salinity and DO levels in the SCSL.

Several studies have been carried out on salinity effects on lobsters' embryonic development (Aiken and Waddy, 1986; Charmantier and Aiken, 1987), on larvae (Sastry and Vargo, 1977) and also on juveniles and adults (Aiken and Waddy, 1986; Vidya and Shoji, 2012) and for different sexes (Jury, 1992). According to these studies, salinity levels significantly affect them biologically and too much freshwater can cause their cells to swell, leading to mortality. Lobsters have been found dead in their dens following abnormally low salinities caused by high winds and heavy spring runoff. Low salinity is more stressful at higher seawater temperatures (Thomas and White, 1969), metabolically stressful and energetically costly for lobsters and salinity below 10 may result in mortality (Jury, 1992). Results of the present study indicated that the scalloped spiny lobster, $P$. homarus usually prefer 35-37 ppt salinity range showing high abundance in the selected sites of the SCSL. Freshwater intake near Patanagalle, Godawaya and Weligama sites could be attributed to the reduction in the salinity as compared to Hikkaduwa site.
There are several reports on the DO requirement of lobsters at various stages of development (Miller et al., 1992; Poucher et al., 1992). In such a dynamic environment, DO of upper water layer always fluctuate and with the increasing depth, DO is reduced and fixed. DO of the selected sites in this study ranged from $5.9 \mathrm{mg} \mathrm{l}^{-1}$ (Godawaya) to $8.1 \mathrm{mg} \mathrm{l}^{-1}$ (Hikkaduwa), which could be the tolerable DO range for high abundance of scalloped spiny lobsters in the SCSL. Hikkaduwa site showed more DO levels than other sites which could be due to greater coral substrate which increases dissolved oxygen in water by wave action. According to the results of the current study, it has been indicated that lobsters prefer low DO levels.

Benthic habitat characteristics are vital for the fourth-stage or post-larval lobsters which is a transitional stage between a free-swimming to benthic existence. If a substrate is not suitable, larvae return to the pelagic form and search a preferable habitat again. Post-larval spiny lobsters prefer macroalgal covered rock substrates, followed by rock-on-sand, mud and sand substrates (Barshaw and Bryant-Rich, 1988) and small lobsters choose gravel substrates over silt-clay substrates (Pottle and Elner, 1982). Flat sandy or muddy habitats with no shelters are less preferred by young lobsters (Cobb, 1971), but adults usually use sand areas for foraging in nights. According to Wahle and Steneck (1991), the early-benthic-phase (EBP) of lobsters in the range of 5 - $40 \mathrm{~mm}$ CL (claw length) were most commonly found in cobble habitats and rarely found in featureless mud, sand or bedrock substrates where larger lobsters were common. Shelters under eelgrass, rocks and boulders are of prime importance to lobsters (Karnofsky et al., 1989) and are used as a retreat from predators and adverse environmental conditions (Lavalli and Barshaw, 1986).

Adult lobsters are relatively hardy and can survive a range of environmental conditions in a variety of habitats. Their preferred habitat is dependent on several 
correlated factors such as temperature, salinity, DO and benthic substrates. Current study provides an insight into the spatial distribution patterns of selected habitat characteristics for $P$. homarus, using GPS technology in the SCSL. Interestingly, the results suggest that $P$. homarus has chosen diverse habitats in different regions of the SCSL. However, the observed abundance of $P$. homarus in the south-east region was higher than the south-west of the SCSL, where the substrates comprise rocks and sand. Although Hikkaduwa and Patanagalle (Yala) sites are named as nature reserves, Patanagalle is less affected by human influences and thus has lower pollution levels. These factors also could be reasons for the high abundance of $P$. homarus in Patanagalle than in the other sites. The data and observations from this study could be utilised as reference materials for future lobster culture programs especially in the site selection process. Patanagalle site could be suggested as the most suitable habitat area to implement future lobster culture programs of $P$. homarus under proper conservation and management strategies.

The next step in understanding long term effect of changes of environmental parameters and bottom substrate types should be an integrated physiological approach including the studies of body fluid, osmosis, respiration, excretion, feeding and behaviour of spiny lobsters. Such detailed investigations would possibly provide the necessary data to assess the effects of constant and fluctuating habitat conditions. It is also required to improve the knowledge of the fisheries ecology of lobsters in the area in order to make the corresponding adjustments to the management plan, if a viable population is expected.

\section{Acknowledgements}

The authors express their gratitude to Department of Wildlife and Conservation (DWC) in Sri Lanka for providing permission to carry out the study in the selected nature reserves. The authors are also thankful to E. P. S. K. Ediriweera, Senior Lecturer, Uva Wellassa University, Badulla for editing and comments for improving the manuscript. The study was funded by the grant Transforming University of Ruhuna into International Status (TURIS) - Pro 45, offered by University of Ruhuna, Matara, Sri Lanka.

\section{References}

Aiken, D. E. and Waddy, S. L. 1986. Environmental influence on recruitment of the American lobster, Homarus americanus; a perspective. Can. J. Fish. Aquat. Sci., 43: 2258-2270.

Barshaw, D. E. and Bryant-Riich, D. R. 1988. A long term study on the behaviour and survival of early juvenile American lobster Homarus americanus, in three naturalistic substrates: eelgrass, mud and rocks. Fish. Bull., 86(4): 789-796.

Bindhu, V., Radhakrishnana, E. V. and Abinash, P. 2007. Effect of environmental parameters on immune response of the Indian spiny lobster, Panulirus homarus (Linnaeus, 1758). Fish Shellfish Immunol., 23: 928-936.

Chamantier, G. and Aiken, D. E. 1987. Osmotic regulation in late embryos and prelarvae of the American lobster Homarus americanus H. Milne-Edwards, 1837 (Crustacea, Decapoda). J. Exp. Mar. Biol. Ecol., 109: 101-108.

Charmantier, G., Charmantier-Daures, M. and Aiken, D. E. 1991. Metamorphosis in the lobster Homarus (Decapoda): a review. J. Crust. Biol., 11(4): 481-495.

Cheng, W. and Chen, J. C. 2000. Effects of pH, temperature and salinity on immune parameters of the freshwater prawn, Macrobrachium rosenbergii. Fish shellfish Immunol., 10: 387-391.

Cheng, W. and Chen, J. C. 2002. The virulence of Enterococcus to freshwater prawn Macrobrachium rosenbergii and its immune resistance under ammonia stress. Fish shellfish Immunol., 12: 97-109.

Childress, M. J. and Herrnkind, W. F. 1996. The ontogeny of social behaviour among juvenile Caribbean spiny lobsters. Animal Behaviour, 51: 675-687.

Cobb, J. S. 1971. The shelter-related behaviour of the lobster Homarus americanus. Marine Tech. Rep., University of Rhode Island, 48: $32 \mathrm{pp}$.

Cooper, R. A. and Uzmann, J. R. 1980. Ecology of juvenile and adult Homarus. In: Cobb, J. S. and Phillips, B. F. (Eds.), The biology and management of lobsters, Vol. II. Ecology and management, p. 97-142.

Crear, B. J., Thomas, C. W., Hart, P. R. and Carter, C. G. 2000. Growth of juvenile southern rock lobsters, Jasus edwardsii, is influenced by diet and temperature, whilst survival is influenced by diet and tank environment. Aquaculture, 190: 169-182.

Davidson, R. J., Villouta, E., Cole, R. G. and Barrier, R. G. F. 2002. Effects of marine reserve protection on spiny lobster (Jasus edwardsii) abundance and size at Tonga Island marine reserve, New Zealand. Aquatic Conserv. Mar. Freshw. Ecosyst., 12: 213-227.

Dubber, G. G., Branch, G. M. and Atkinson, L. J. 2004. The effects of temperature and diet on the survival, growth and food uptake of aquarium held post-pueruli of the rock lobster Jasus lalandii. Aquaculture, 240: 249-266.

Evans, C. G., Lockwood, A. P. M and Evans, A. J. 1996. Field studies of the population dynamics of the spotted spiny lobster, Panulirus guttatus (Latreille) at Bermuda. Gulf Mex. Sci., 14: 55-65.

Hartnoll, R. G. 1982. Growth. In: Bliss, D. E. (Ed.), The biology of crustacea. Academic Press, New York, p. 111-196. 
Holthuis, L. B. 1991. FAO species catalogue 13. Marine lobsters of the world. An annotated and illustrated catalogue of species of interest to fisheries known to date. FAO Fisheries Synopsis 125, Rome, 292 pp.

Holthuis, L. B. 1995. Marine lobsters of the world of interest to fisheries. FAO Species Catalogue 13. UNESCO Publishing, Paris, France, 112 pp.

Hughes, J. T. and Matthiessen, G. C. 1962. Observations on the biology of the American lobster, Homarus americanus. Limnol. Oceanogr., 7(3): 129-133.

Jayawickrema, S. J. C. 1991. Fishery and population dynamics of Panulirus homarus (Linnaeus) from Mutwal, Sri Lanka. J. Nat. Sci. Counc. Sri Lanka, 19(1): 53-62.

Jong-Kuk, C., Hyun-Joo, O., Bon, J. K., Saro, L. and Joo-Hyung, R. 2011. Macrobenthos habitat mapping in a tidal flat using remotely sensed data and a GIS-based probabilistic model. Mar. Poll. Bull., 62: 564-572.

Jury, S. H. 1992. The effects of salinity on the physiology and behaviour of estuarine lobsters (Homarus americanus). NOAA Contr. Rep. NA89EA-H-00015. National Marine Fisheries Service, Milford, $66 \mathrm{pp}$.

Karnofsky, E. B., Atema, J. and Elgin, R. H. 1989. Field observations of social behaviour, shelter use and foraging in the lobster, Homarus americanus. Biol. Bull., 176: $239-246$.

Kemp, J. O. G. and Britz, P. J. 2008. The effect of temperature on the growth, survival and food consumption of the east coast rock lobster Panulirus homarus rubellus. Aquaculture, 280: 227-231.

Kulmiye, A. J. and Mavuti, K. M. 2005. Growth and moulting of captive Panulirus homarus homarus in Kenya, western Indian Ocean. New Zealand J. Mar. Freshw. Res., 39: 539-549.

Lamela, R., Coffigny, R., Quintana, Y. and Martinez, M. 2005. Phenoloxidase and peoxidase activity in the shrimp Litopenaeus schmitti, Perez-Farfante and Kensley exposed to low salinity. Aquac. Res., 36: 1293-7.

Lavalli, K. L. and Barshaw, D. E. 1986. Burrows protect post-larval lobster Homarus americanus from predation by the non-burrowing cunner, Tautogolabrus adspersus, but not from the burrowing mud crab Neopanope texani. Mar. Ecol. Prog. Ser., 32: 13-16.

Le Moullac, G., Soyez, C., Saulnier, D., Ansquer, D., Avarre, J. C. and Levy, P. 1998. Effect of hypoxia stress on the immune response and the resistance to vibriosis of the shrimp Penaeus stylirostris. Fish Shellfish Immunol., 8: 621-9.

Legendre, P. and Legendre, L. 1998. Numerical ecology. Elsevier, Amsterdam.

Lellis, W. A. and Russell, J. A. 1990. Effect of temperature on survival, growth and feed intake of post-larval spiny lobsters, Panulirus argus. Aquaculture, 90: 1-9.
Liebhold, A. M. and Gurevitch, J. 2002. Integrating the statistical analysis of spatial data in ecology. Ecography, 25: 553-557.

Miller, D. C., Poucher, S. L. and Coiro, L. L. 1992. Development of dissolved oxygen criteria for Long Island Sound: The acute effects database. Proceedings of the Long Island Sound Research Conference, 23-24 October, Southern Connecticut State University, $23 \mathrm{pp}$.

Perkins, H. C. 1972. Development rates at various temperatures of embryos of the northern lobster (Homarus americanus Milne-Edwards). Fish. Bull., 70(1): 95-99.

Phillips, B. F., Campbell, N. A. and Rea, W. A. 1977. Laboratory growth of early juveniles of the western rock lobster Panulirus longipes cygnus. Mar. Biol., 39: 31-39.

Phillips, B. F., Cobb, J. S. and George, R. W. 1980. General biology. In: Cobb, J. S., Phillips, B. F. (Eds.), The biology and management of lobsters, vol. I, Physiology and behaviour, Academic Press, New York, 89 pp.

Pottle, R. A. and Elner, R. W. 1982. Substrate preference behaviour of juvenile American lobsters, Homarus americanus, in gravel and silt-clay sediments. Can. J. Fish. Aquat. Sci., 39: 928-932.

Poucher, S. L., Coiro, L. L. and Miller, D. C. 1992. Development of dissolved oxygen criteria for Long Island Sound: sub-acute effects (Abstract), Long Island Sound Research Conference, 23-24 October, Southern Connecticut State University, New Haven, Connecticut.

Rogers, B. A., Cobb, J. S. and Marshall, N. 1968. Size comparisons of inshore and offshore larvae of the lobster, Homarus americanus, off southern New England. Proceedings of the National Shellfisheries Association, 5: 78-81.

Sastry, A. N. and Vargo, S. L. 1977. Variations in the physiological responses of crustacean larvae to temperature. In: Vernberg, F. J., Calabrese A., Thurberg, F. P., Vernberg, W. B. (Eds.), Physiological responses of marine pollutants. Academic press, New York, p. 401-423.

Serfling, S. A. and Ford, R. F. 1975. Laboratory culture of juvenile stages of the California spiny lobster Panulirus interruptus (Randall) at elevated temperatures. Aquaculture, 6: 377-387.

Sebens, K. P. 1991. Habitat structure and community dynamics in marine benthic systems. In: Bell, S. S., McCoy, E. D. and Mushinsky, H. R. (Eds.), Habitat structure: the physical arrangement of objects in space, Chapman and Hall, New York, p. 211-234,

Strickland, J. D. H. and Parsons, T. R. 1968. Determination of dissolved oxygen. Bull. Fish. Res. Board Can., 167: 71-75.

Thomas, M. L. H. and White, G. N. 1969. Mass mortality of estuarine fauna at Bideford, P. E. L., associated with abnormally low salinities. J. Fish. Res. Board Can., 26: 701-704. 
Thomas, C. W., Crear, B. J. and Hart, P. R. 2000. The effect of elevated temperature on survival, growth, feeding and metabolic activity of the southern rock lobster, Jasus edwardsii. Aquaculture, 185: 73-84.

Upul, L. 2009. Status of the South coast lobster fishery. CENARA Project Reports on lobsters, p. 1-10.

Vargas-Albores, F., Baltazar, P. H., Clark, G. D. and Barajas, F. M. 1998. Influence of temperature and salinity on the yellow leg shrimp, Penaeus californiensis Holmes, prophenoloxidase system. Aquac. Res., 29: 549-53.

Vidya, K. and Shoji, J. 2012. Effect of salinity on growth and survival of juvenile Indian spiny lobster, Panulirus homarus (Linnaeus). Indian J. Fish., 59(1): 113-118.

Wahle, R. A. and Steneck, R. S. 1991. Recruitment habitats and nursery grounds of the American lobster; a demographic bottleneck? Mar. Ecol. Prog. Ser., 69: 231-243. 